\title{
Оптические свойства InGaAs/InAlAs метаморфных наногетероструктур для фотопреобразователей лазерного и солнечного излучения
}

\author{
(C) В.М. Емельянов, Н.А. Калюжный, С.А. Минтаиров, М.З. Шварц
}

Физико-технический институт им. А.Ф. Иофрфе РАН,

Санкт-Петербург, Россия

E-mail: vm.emelyanov@mail.ioffe.ru

Поступило в Редакцию 25 июня 2018 г.

Методом спектроскопии отражения на специально созданных гетероструктурах брэгговских отражателей определены показатели преломления наноразмерных слоев $\operatorname{In}_{x} \mathrm{Al}_{y} \mathrm{Ga}_{1-x-y} \mathrm{As}$ и $\mathrm{In}_{x} \mathrm{Al}_{1-x} \mathrm{As}$ с концентрациями индия $x=0.21-0.24$ и алюминия $y=0,0.10,0.20$ в диапазоне длин волн $700-2000 \mathrm{~nm}$. Продемонстрирована применимость метода, основанного на анализе авто- и кросс-корреляционных коэффициентов производных по длине волны в зависимости от величины отражения таких структур для нахождения дисперсионных кривых материалов, формирующих отражатель. Установлено, что увеличение концентрации индия в InGaAs и AlInAs приводит к существенному росту показателя преломления при сохранении спектрального хода значений показателя преломления, характерного для арсенида галлия и арсенида алюминия.

DOI: $10.21883 /$ PJTF.2018.19.46682.17434

Прогресс в метаморфной технологии создания полупроводниковых гетероструктур InGaAs на подложках $\mathrm{GaAs}$ позволил получить фотоэлектрические преобразователи (ФП) с границей фоточувствительности 930-1200 nm при высоком квантовом выходе фотоответа и рабочем напряжении [1-3]. Такие структуры могут быть использованы для формирования субэлементов в многопереходных фотопреобразователях, a также для приемников-преобразователей лазерного излучения. Для ФП лазерного излучения $\mathrm{In}_{0.24} \mathrm{Ga}_{0.76} \mathrm{As} / \mathrm{GaAs}$ с длиной волны $1064 \mathrm{~nm}$, находящих применение в системах оптической передачи энергии [4], 
достигнуты рекордные для ФП этого спектрального диапазона значения КПД более $40 \%$ [3].

Получение максимально возможных, приближающихся к термодинамическому пределу значений эффективности ФП лазерного излучения требует тщательно продуманного оптического дизайна гетероструктур. Это особенно актуально для ФП с большим количеством наноразмерных слоев и сильным проявлением интерференционных эффектов. Например, для многопереходных ФП, где необходимо обеспечить согласование субэлементов по фототокам, а также для ФП со встроенными фотонными кристаллами и брэгговскими отражателями (БО). Последние могут использоваться с целью улучшения собирания фотогенерированных носителей заряда и повышения рабочего напряжения за счет двукратного прохождения и рециклирования излучения в фотоактивных слоях, что позволяет уменьшать их толщину без снижения эффективности поглощения света [5-7].

Метаморфные ФП InGaAs/GaAs с расширенной до $1100 \mathrm{~nm}$ спектральной чувствительностью формируются на основе слоев твердых растворов $\operatorname{In}_{x} \mathrm{Al}_{y} \mathrm{Ga}_{1-x-y} \mathrm{As}$ с содержанием индия $x=0.21-0.24$, экспериментальных данных об оптических свойствах которых пока недостаточно.

В настоящей работе приведены результаты исследования показателя преломления наноразмерных слоев $\operatorname{In}_{x} \mathrm{Al}_{y} \mathrm{Ga}_{1-x-y} \mathrm{As}$ c $x=0.21-0.24$ и $y=0-0.79$, представляющих интерес для проектирования БО, в области их относительной спектральной прозрачности.

При применении к метаморфным слоям методов эллипсометрии и рефлектометрии для определения их показателей преломления и поглощения возникают некоторые сложности, обусловленные невозможностью получения одиночного слоя полупроводника на подложке с известными параметрами. Вследствие паразитного отражения от метаморфного „буфера“ [1] (необходимого в таких структурах для компенсации кристаллографического рассогласования) имеются искажения наблюдаемого оптического сигнала, вид которых априорно неизвестен. Это особенно сильно проявляется в области прозрачности или слабого поглощения исследуемых слоев.

Возможным решением описанной проблемы является использование для измерений специальных структур с БО, формирующими контрастную интерференционную картину и имеющими выраженный главный максимум отражения. С ростом числа периодов отражателя

4* Письма в ЖТФ, 2018, том 44, вып. 19 


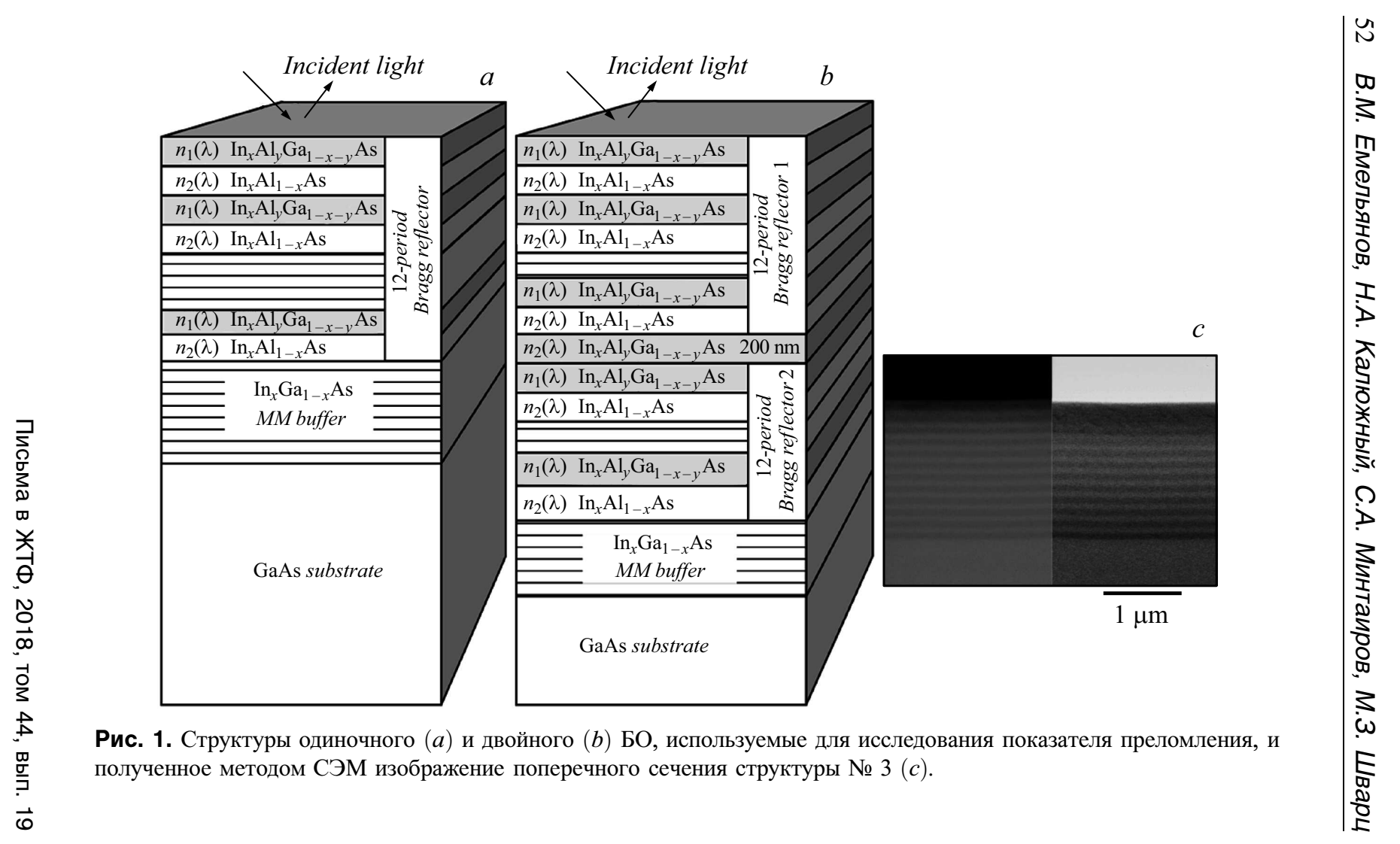


увеличивается влияние на наблюдаемый спектр слоев, входящих в БО, и сокращается вклад слоев, лежащих под ним.

Определение дисперсионных кривых для пары материалов $\mathrm{In}_{x} \mathrm{Al}_{y} \mathrm{Ga}_{1-x-y} \mathrm{As} / \mathrm{In}_{x} \mathrm{Al}_{1-x} \mathrm{As}$ в области слабого поглощения и монотонности хроматической дисперсии требует формирования пары БО, настроенных резонансно на разные диапазоны длин волн. Предметом анализа является функция, значение которой должно быть минимизировано:

$$
\beta\left(R_{1}, R_{0}\right)=\left[\Psi\left(\partial R_{0} / \partial \lambda\right)-K\left(\partial R_{0} / \partial \lambda, \partial R_{1} / \partial \lambda\right)\right] \sigma_{K}^{-1},
$$

где $\Psi-$ коэффициент автокорреляции, $K-$ коэффициент кросс-корреляции, $\sigma_{K}$ - среднеквадратичное отклонение расчета коэффициента кросс-корреляции, $\lambda$ - длина волны излучения, $R_{1}-$ измеренный коэффициент отражения от структуры, $R_{0}$ - коэффициент отражения, рассчитанный по методу матриц переноса [8] в отсутствие поглощения.

При этом в пределах окна анализа дисперсионные кривые для двух материалов $n_{1}(\lambda)$ и $n_{2}(\lambda)$ допустимо аппроксимировать следующими простыми соотношениями:

$$
n_{1}(\lambda)=n_{10}+\gamma_{1} \lambda^{-2}, \quad n_{2}(\lambda)=n_{20}+\gamma_{2} \lambda^{-2} .
$$

Формула (1) имеет физический смысл соотношения сигнал/шум для измеренного коэффициента отражения. Начальное приближение для искомого решения строится по положениям и ширине главных максимумов двух БО. На этом этапе толщины слоев, входящих в отражатели, соответствуют заданным при росте значениям. Затем при решении системы нормальных уравнений относительно (1) вида $\partial \beta / \partial z_{i}=0(\mathbf{z}-$ вектор варьируемых параметров) происходит уточнение дисперсионной кривой и толщин слоев БО по всем участкам измеренного спектра отражения, для которых имеется достаточный контраст минимумов и максимумов интерференционной картины.

Экспериментальные структуры БО (рис. $1, a, b)$ были изготовлены для измерения спектральных зависимостей показателя преломления твердых растворов $\operatorname{In}_{x} \mathrm{Al}_{y} \mathrm{Ga}_{1-x-y} \mathrm{As}$ и $\operatorname{In}_{x} \mathrm{Al}_{1-x} \mathrm{As}$ в диапазоне длин волн 700-2000 nm. Параметры исследованных структур приведены в таблице. Все образцы, кроме образца № 4, соответствовали рис. 1, $a$ и имели один БО. Образец № 4 соответствовал рис. $1, b$ и имел два БО, выращенных один над другим и настроенных на разные длины волн. Более длинноволновый отражатель находился глубже в

Письма в ЖТФ, 2018, том 44, вып. 19 
Параметры исследованных структур метаморфных БО $\operatorname{In}_{x} \mathrm{Al}_{y} \mathrm{Ga}_{1-x-y} \mathrm{As} / \mathrm{In}_{x} \mathrm{Al}_{1-x} \mathrm{As}$

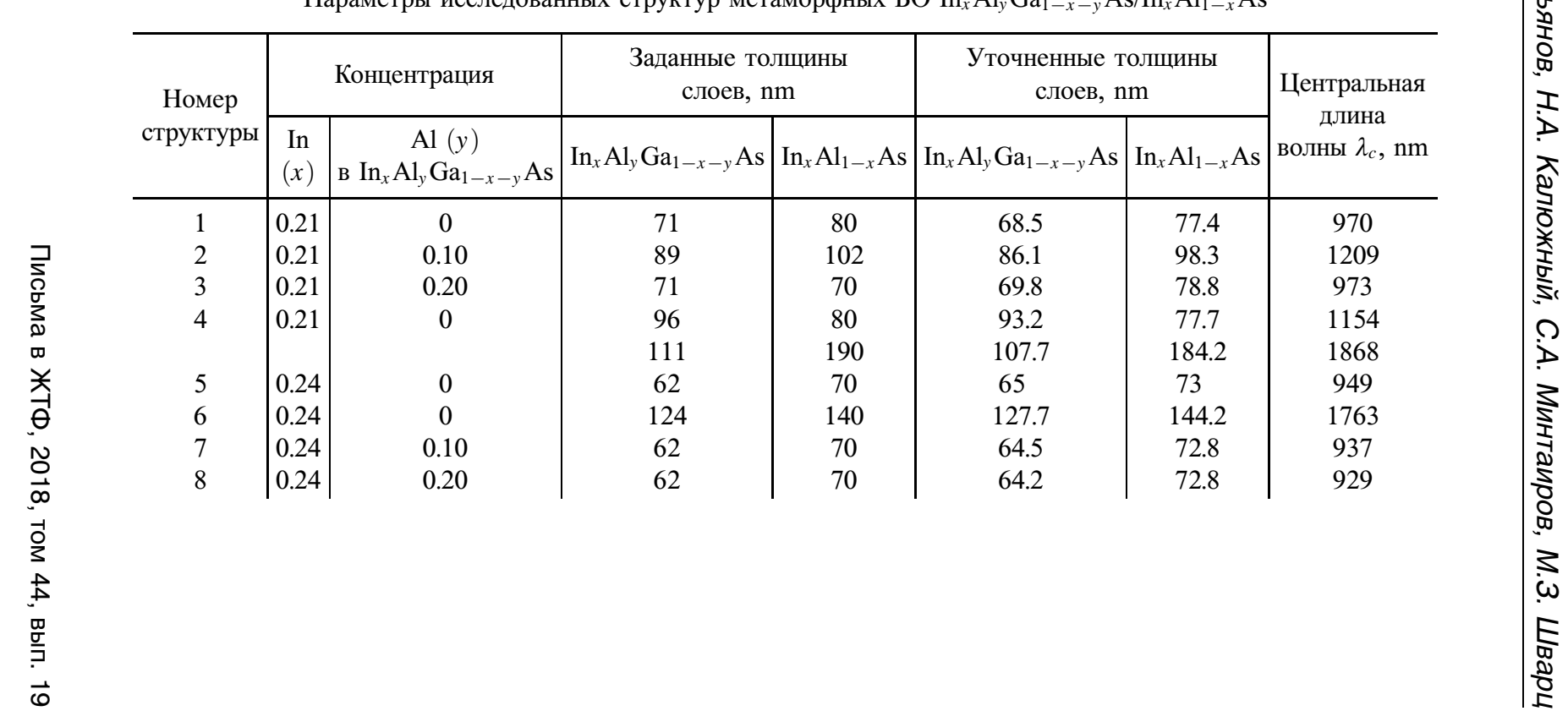


структуре. Такая организация позволяет получить оба БО в ходе одного технологического процесса и снизить влияние погрешностей скоростей роста на измеряемые оптические параметры.

Образцы изготавливались методом МОС-гидридной эпитаксии (МОС - металлоорганические соединения) в горизонтальном реакторе при давлении 100 mbar. В качестве источников элементов III группы использовались триметилгаллий, триметилиндий и триметилалюминий, a V группы - арсин. Рост проводился на подложках GaAs ориентации (100), разориентированных на $6^{\circ}$ к направлению [111] в кристалле. Метаморфный буферный слой формировался из слоев толщиной $200 \mathrm{~nm}$ с шагом $x=0.035$ по концентрации индия. Описанная технология обеспечивала хорошую морфологию поверхности и эффективный „загиб“ пронизывающих дислокаций внутрь метаморфного „буфера“.

Для каждой из гетероструктур измерялись и моделировались спектры отражения. Использованные при расчетах значения показателей преломления и толщин слоев БО варьировались до обеспечения минимизации функции контраста (1). Дополнительно толщины слоев экспериментальных гетероструктур независимо контролировались методом сканирующей электронной микроскопии (СЭМ). Изображение поперечного среза одного из образцов представлено на рис. 1, $c$. Уточненные при решении системы нормальных уравнений значения толщин слоев БО отличаются от заданных при росте менее чем на 5\%, что удовлетворительно согласуется с результатами СЭМ.

Полученные спектры отражения для гетероструктур № 3-6 приведены на рис. 2. Имеется различие расчетных и экспериментальных зависимостей, что связано с отсутствием учета поглощения при моделировании, а также с влиянием дополнительных факторов, искажающих общую интерференционную картину. Тем не менее положения интерференционных максимумов и минимумов достаточно точно совпадают для всех образцов. Роль поглощения хорошо видна при сравнении структур № 3 и 5: так, слои $\operatorname{In}_{0.21} \mathrm{Al}_{0.2} \mathrm{Ga}_{0.59} \mathrm{As}$ прозрачны в диапазоне длин волн 900-1000 nm, в то время для слои $\mathrm{In}_{0.24} \mathrm{Ga}_{0.76} \mathrm{As}$ - достаточно сильно поглощают излучение. По этой причине максимум отражения для образца № 5 оказывается меньше 80\%. Для структуры № 4 следует отметить, что, несмотря на существенные отличия толщин слоев обоих БО от оптимальных (равных $n \lambda_{c} / 4$ для центральной длины волны $\lambda$ отражателя), были получены четкие и выраженные максимумы отражения.

Письма в ЖТФ, 2018, том 44, вып. 19 


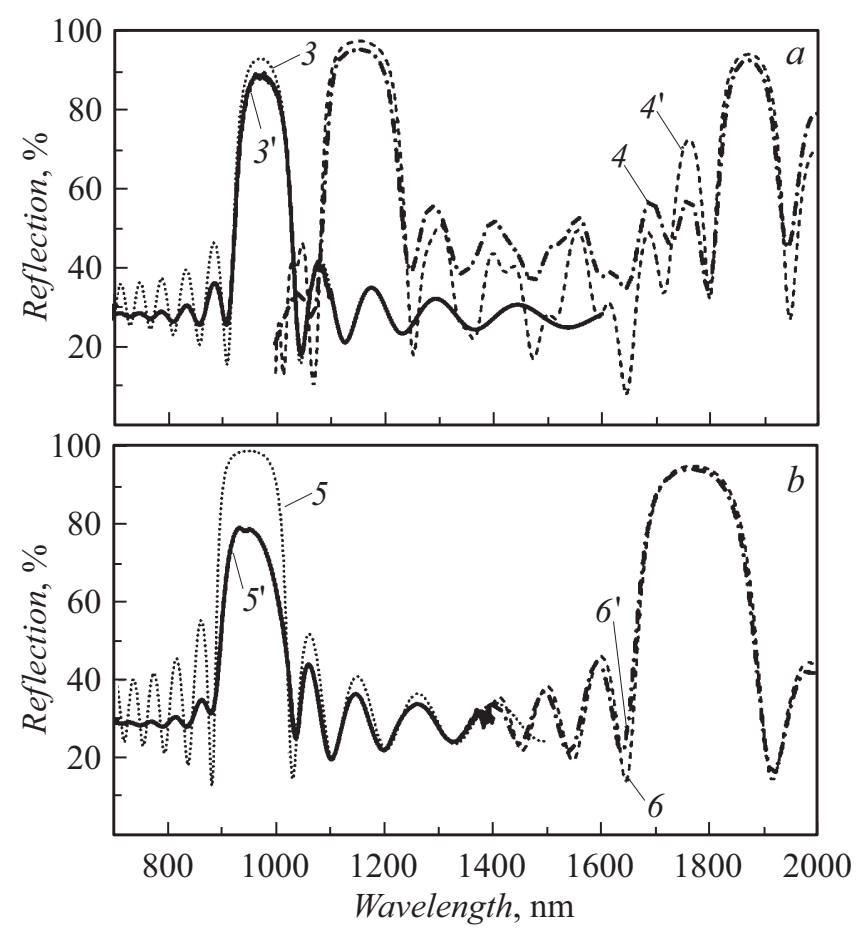

Рис. 2. Расчетные $(3-6)$ и экспериментальные $\left(3^{\prime}-6^{\prime}\right)$ зависимости коэффициента отражения для структур с БО. Номера кривых соответствуют номерам структур в таблице.

Определенные при анализе спектров отражения БО, специально сформированных методом МОС-гидридной эпикаксии, дисперсионные кривые для твердых растворов $\operatorname{In}_{x} \mathrm{Al}_{y} \mathrm{Ga}_{1-x-y} \mathrm{As}$ представлены на pис. 3, на котором также приведены известные литературные данные по спектральным зависимостям показателей преломления материалов GaAs, AlAs и $\operatorname{In}_{0.53} \mathrm{Ga}_{0.47} \mathrm{As}[9-11]$.

Различия в значениях показателей преломления для материалов с концентрациями индия $x=0.21$ и 0.24 оказываются несущественными. В диапазонах длин волн 700-1000 и $1500-2000 \mathrm{~nm}$ показатель преломления $\mathrm{In}_{0.24} \mathrm{Ga}_{0.76}$ As превосходит значения для GaAs на 0.25 и 0.1 по 


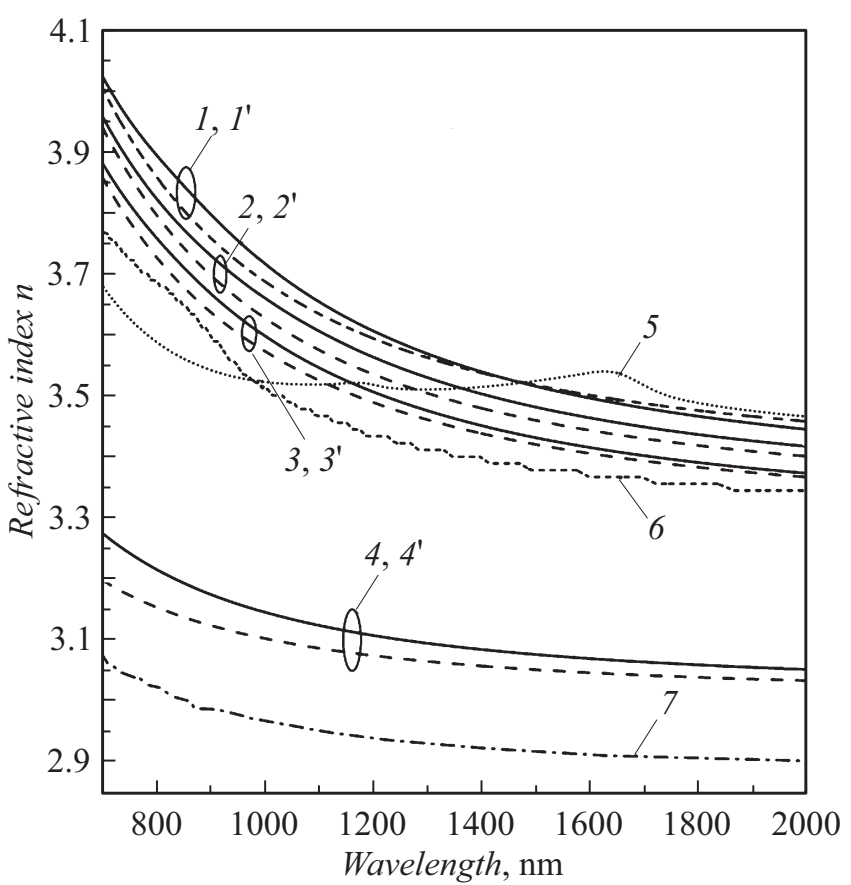

Рис. 3. Дисперсионные зависимости показателя преломления, полученные для наноразмерных метаморфных слоев с концентрацией In $x=0.24$ (сплошные линии $1-4$ ) и $x=0.21$ (штриховые линии $1^{\prime}-4^{\prime}$ ), в сравнении с данными для объемных материалов (5-7): 1, $1^{\prime}-\operatorname{In}_{x} \mathrm{Ga}_{1-x} \mathrm{As}, 2,2^{\prime}-\mathrm{In}_{x} \mathrm{Al}_{0.1} \mathrm{Ga}_{0.9-x} \mathrm{As}$, 3, $3^{\prime}-\mathrm{In}_{x} \mathrm{Al}_{0.2} \mathrm{Ga}_{0.8-x} \mathrm{As}, 4,4^{\prime}-\mathrm{In}_{x} \mathrm{Al}_{1-x} \mathrm{As}, 5-\mathrm{In}_{0.53} \mathrm{Ga}_{0.47} \mathrm{As}$ [9], $6-$ GaAs [10,11], 7 - AlAs [10].

абсолютной величине соответственно. Общим среди всех рассматриваемых метаморфных материалов является ход дисперсионных кривых, который повторяет ход характерных для арсенида галлия зависимостей. В случаe $\operatorname{In}_{0.24} \mathrm{Al}_{0.76} \mathrm{As}$ отличие от $\mathrm{AlAs}$ составляет приблизительно 0.15 во всем спектральном диапазоне при незначительном увеличении дисперсии. Следует отметить, что определенные величины показателя преломления для наноразмерных метаморфных слоев $\operatorname{In}_{0.24} \mathrm{Al}_{0.76} \mathrm{As}$ и $\mathrm{In}_{0.21} \mathrm{Al}_{0.79} \mathrm{As}$ на значительном интервале длин волн $(700-1500 \mathrm{~nm})$

Письма в ЖТФ, 2018, том 44, вып. 19 
превосходят соответствующие значения для $\mathrm{In}_{0.53} \mathrm{Ga}_{0.47} \mathrm{As}$, известные из литературы. Введение в InGaAs небольшой концентрации алюминия $y$ для сдвига края поглощения уменьшает его показатель преломления приблизительно на $\Delta n \approx 0.4 y$ без изменения формы дисперсионной кривой.

Предложенный метод определения показателей преломления наноразмерных слоев $\operatorname{In}_{x} \mathrm{Al}_{y} \mathrm{Ga}_{1-x-y} \mathrm{As}$ и $\operatorname{In}_{x} \mathrm{Al}_{1-x} \mathrm{As} \quad(x=0.21-0.24$, $y=0-0.20)$ показал свою применимость при использовании спектральной рефлектометрии в качестве источника первичных экспериментальных данных для специально сформированных на основе указанных материалов брэгговских отражателей. Полученные дисперсионные зависимости показателя преломления могут быть использованы при проектировании многослойных гетероструктур фотопреобразователей, в первую очередь многопереходных с метаморфными слоями, а также имеющих встроенные БО, фотонные кристаллы.

Работа выполнена при поддержке Российского фонда фундаментальных исследований (грант № 16-29-03216 офи_м).

\section{Список литературы}

[1] Рыбальченко Д.В., Минтаиров С.А., Салий Р.А., Тимошина Н.X., Швари, М.З., Калюжный Н.А. // ФТП. 2017. Т. 51. В. 1. С. 94-100.

[2] Минтаиров С.А., Емельянов В.М., Рыбальченко Д.В., Салий Р.А., Тимошина Н.Х., Швари М.3., Калюжсный Н.А. // ФТП. 2016. Т. 50. В. 4. С. 525-530.

[3] Kalyuzhnyy N.A., Mintairov S.A., Nadtochiy A.M., Nevedomskiy V.M., Rybalchenko D.V., Shvarts M.Z. // Electron. Lett. 2017. V. 53. N 3. P. 173-175.

[4] Dumke M., Heiserich G., Franke S., Schulz L., Overmeyer L. // J. Syst. Cybernet. Inform. 2010. V. 8. P. 55.

[5] Lantratov V.M., Kochnev I.V., Shvarts M.Z. // Proc. of the 27th SOTAPOCS Electrochemical Society. 1997. V. 97-21. P. 125.

[6] Shvarts M.Z., Chosta O.I., Kochnev I.V., Lantratov V.M., Andreev V.M. // Solar Energy Mater. Solar Cells. 2001. V. 68. N 1. P. 105-122.

[7] Емельянов В.М., Калюжный Н.А., Минтаиров С.А., Швари М.З., Лантратов В.М. // ФТП. 2010. Т. 44. В. 12. С. 1649-1654.

[8] Abeles F. //Ann. de Phys. 1950. V. 5. N 5. P. 596-640.

[9] Adachi S. // J. Appl. Phys. 1989. V. 66. N 12. P. 6030-6040.

[10] Aspnes D.E., Kelso S.M., Logan R.A., Bhat R. // J. Appl. Phys. 1986. V. 60. N 2. P. 754-767.

[11] Пихтин А.Н., Яськов А.Д. // ФТП. 1980. Т. 14. № 4. С. 389-392.

Письма в ЖТФ, 2018, том 44, вып. 19 